\title{
Magnitude of Maternal Anaemia in Rural Burkina Faso: Contribution of Nutritional Factors and Infectious Diseases
}

\author{
Nicolas Meda, ${ }^{1,2}$ Malik Coulibaly, ${ }^{1}$ Yacouba Nebie, ${ }^{2}$ Ibrahima Diallo, ${ }^{1}$ \\ Yves Traore, ${ }^{2}$ and Laurent T. Ouedraogo ${ }^{2,3}$ \\ ${ }^{1}$ Centre MURAZ, P.O. Box 390, Bobo-Dioulasso, Burkina Faso \\ ${ }^{2}$ Université de Ouaga I Pr. Joseph Ki-Zerbo, P.O. Box 7021, Ouagadougou, Burkina Faso \\ ${ }^{3}$ Institut Regional de Santé Publique, Ouidah, Benin \\ Correspondence should be addressed to Nicolas Meda; nicolas.meda@centre-muraz.bf
}

Received 4 July 2016; Accepted 20 October 2016

Academic Editor: Carol J. Burns

Copyright (C) 2016 Nicolas Meda et al. This is an open access article distributed under the Creative Commons Attribution License, which permits unrestricted use, distribution, and reproduction in any medium, provided the original work is properly cited.

Background. Maternal anaemia is a worldwide public health problem affecting particularly developing countries. In Burkina Faso, little data is available for rural areas. This study aimed to determine the prevalence of maternal anaemia and the risk factors associated with it in the rural health district of Hounde in Burkina Faso but also to define better control measures of maternal anaemia. Methods. This cross-sectional study conducted in 2010 had a sample of 3,140 pregnant women attending antenatal care in all the 18 primary health care facilities of the district. The women's characteristics and their knowledge about contraceptives and sexually transmitted infections (STI) were collected. Also, physical and gynaecological examination, completed by vaginal, cervix, blood, and stool samplings, were collected. Results. A prevalence of $63.1 \%$ was recorded for maternal anaemia. Geophagy rate was $16.3 \%$ and vitamin A deficiency $69.3 \%$. In addition, anaemia was independently associated with low education, low brachial perimeter, geophagy, and primigravida. But no statically significant relationship was found between maternal anaemia and infectious diseases or vitamin A deficiency. Conclusion. The magnitude of maternal anaemia was found to be higher in rural Hounde health district and should be addressed by adequate policy including education and the fight against malnutrition.

\section{Introduction}

Anaemia during pregnancy or maternal anaemia is globally defined by blood haemoglobin $(\mathrm{Hb})$ rate inferior to $11 \mathrm{~g} / \mathrm{dL}$ $[1,2]$. Although maternal anaemia is highly prevalent in the world, it particularly affects developing countries. In Africa, according to World Health Organization, maternal anaemia affects $57.1 \%$ of pregnant women, classifying anaemia during pregnancy as a severe public health problem [2].

The primary cause of anaemia is iron deficiency, but its proportion may vary among population groups and in different areas according to the local conditions [3]. The main risk factors for iron deficiency anaemia include a low intake of iron, poor absorption of iron from diets, and period of life when iron requirements are especially high, such as growth and pregnancy [4]. Other causes of anaemia are heavy blood loss, acute and chronic infections, micronutrient deficiencies, and haemoglobinopathies [5].
Maternal anaemia remains a problem of public health significance because of its magnitude and negative outcomes: high risk of maternal and foetal deaths, increase in low-birthweight babies, perinatal mortality, and increase in puerperal infections [2]. Severe anaemia has been associated with increased premature deliveries, caesarean sections, prolonged labour, and preterm delivery [6]. Given the risk posted by maternal anaemia, many developing countries set up programmes to reduce it by iron and folic acid supplementation [7]. However, the programmes have faced difficulties such as logistic and budget problems for a regular supply for health centres, difficult access and poor utilisation of antenatal care services, inadequate counselling, poverty of populations, and low compliance by pregnant women [8]. The low compliance rate is attributed to long treatment with side effects, forgetfulness, and the feeling of not being ill to take tablets $[8,9]$. 
Burkina Faso is a West African resource-limited country with a high prevalence of maternal anaemia due, mainly, to poverty and food shortages [10, 11]. Between 1993 and 1996 we carried out in Bobo-Dioulasso, the second largest city of the country, several cross-sectional studies to estimate the prevalence of maternal anaemia. Overall prevalence of maternal anaemia ranged from $66 \%$ to $72 \%$ [12-14]. At national level, it was estimated in 2003 that $68.3 \%$ of pregnant women suffered from anaemia [2]. Regarding the risk factors, a logistic regression analysis demonstrated that, in urban Burkina Faso, maternal anaemia was significantly and independently related to HIV infection, advanced gestational age, and low socioeconomic status [15].

Addressing the problem of maternal anaemia requires more accurate and representative figures on its magnitude. In Burkina Faso all available statistics mainly report the situation of urban settings while about $80 \%$ of the population lives in rural areas [10]. Therefore, we find an urgent need to address the lack of data in rural Burkina Faso where we postulate a more severe problem of maternal anaemia. Thus, the objective of our study was to determine the prevalence and factors associated with maternal anaemia in a rural part of Burkina Faso: the health district of Houndé.

\section{Methods}

2.1. Study Design and Site. We designed a cross-sectional study carried out from March to June 2010 in the health district of Houndé, a rural area in western Burkina Faso. During the study, the district population amounted to 261856 inhabitants and lived mainly in traditional agriculture areas. The study site had 18 primary health care facilities covering 99 villages and a district hospital as referral centre. Around 13000 pregnancies were expected per year. The antenatal coverage was near $80 \%$.

2.2. Study Population. The study population was the pregnant women attending antenatal care in all primary health care facilities of the district during the study period. The inclusion criteria were to be pregnant, to consult for antennal care during the study, and to accept the study requirements. We excluded nonpregnant women, nonresident in the health district, and reluctant subjects.

2.3. Study Size. A rapid estimate method of disease prevalence was used in the 18 health centres of the health district to recruit 3,140 pregnant women, that is, approximately onethird of the expected number of pregnant women. The size of each health centre cluster was estimated according to the proportional probability rule based on the population size that each health centre was responsible for. Approximately 150 to 200 pregnant women were selected in each health centre.

2.4. Data Collection. Consecutive inclusion of pregnant women per selected health facility was carried out until reaching the required sample size. A questionnaire was used for data collection. It included information related to the study population characteristics and their knowledge about contraceptives and sexually transmitted infections. In addition to the above, physical and gynaecological examination, completed by vaginal, cervix, blood, and stool samplings, were carried out. The interviews and examinations were implemented in the health centres by the personnel supervised by four laboratory technicians. The samples were transported to Houndé District Hospital and later transferred to Centre MURAZ, a reference laboratory in Bobo-Dioulasso, Burkina Faso, for microbiological analyses.

2.5. Laboratory Methods. Haemoglobin level was assayed from finger stick sampling with portable haemoglobin metre, HemoCue $^{\circledR}$ [16]. The technique of thick drop and blood smear stained with field rapid method was applied for malaria screening. Trichomonas vaginalis was tested with commercial kit InPouch $^{\mathrm{TM}}$ TV (Biomeds, San Jose, California) and the slide was read with mirror image microscope. The test for Candida albicans was carried out with a vaginal sample sowed in Sabouraud medium supplemented with chloramphenicol. The screening for Neisseria gonorrhoeae and Chlamydia trachomatis was firstly done on the field with rapid tests on swabs, respectively, using GONORGENRapid Swab Test $^{\circledR}$, and CHLAMYGEN-Rapid Chlamydia Swab Test ${ }^{\circledR}$. But the high deviation of our results in comparison to existing data required a change in the method. Gonorrhoea diagnostics was finally based on cervix smear slides, stained with Gram. For Chlamydia trachomatis, direct immunofluorescence method was used on cervix smears (BioMérieux, Lyon, France). Bacterial vaginosis was tested with microscope on vaginal smears after Gram staining. Serological tests were carried out for syphilis, HIV infection, and genital herpes type 2 (HSV). Syphilis was tested with Treponema Pallidum Haemagglutination Assay (TPHA) of Newmarket Laboratories Ltd. (Kentford, UK). All the reactive sera to TPHA were further analysed with the Rapid Plasma Reagin (RPR) slide test of Newmarket Laboratories Ltd. HIV infection was firstly tested with ELISA mix. Murex HIV1.2. ${ }^{\circledR}$ was used in first intention (Abbott, Dartford, UK). Then all the reactive sera to this first test were analysed with Wellcozyme HIV Recombinant and Murex HIV-2 ${ }^{\circledR}$ [13]. Concerning Herpes Simplex Virus Type 2, the HSV-2 test of Human Diagnostics was used for screening. But the high proportion of positive results on the field suggested another test: Herpes Simplex Virus Type 2 (HSV-2) IgG ELISA of GULL-MERIDIAN Laboratories (Homburg, Germany). Vitamin A was assayed by measuring serum retinol level with High Performance Liquid Chromatography. However, the high cost of vitamin A assay commanded the reduction of the sample size to 316 only for this variable, that is, one-tenth of the total sample size. We included in this subgroup all the subjects infected by HIV and those hit by severe anaemia ( $\mathrm{Hb}$ $<7 \mathrm{~g} / \mathrm{dL}$ ). For each case of HIV infection or severe anaemia, two controls were also selected. Finally, helminthiases were screened by standard coprological test using newly laid faeces coupled with Willis enrichment method.

2.6. Data Analysis. Maternal anaemia was considered for $\mathrm{Hb}$ level $<11 \mathrm{~g} / \mathrm{dL}$ and vitamin A deficiency for serum retinol rate $<20 \mu \mathrm{g} / \mathrm{dL}$. Bivariate analysis with chi-square test of 
Pearson was necessary for comparisons between proportions if appropriate or chi-squared exact test of Fisher. Associated factors were assessed with multiple logistic regression. All the analyses were implemented with Stata 11 software package with a $P$ value $\leq 0.20$ as our cut point for inclusion in the model and a $P$ value $\leq 0.05$, for final statistical significance.

2.7. Ethical Clearance. The study protocol was cleared by Centre MURAZ Institutional Review Board and Health Ministry Department of Family Health in Burkina Faso. An informed verbal consent was obtained before the recruitment of participants and confidentiality was guaranteed.

\section{Results}

3.1. Study Population Characteristics. A total of 3,140 pregnant women were included and no refusal was noticed for the interview. Women age ranged from 14 to 49 and the mean was 25.3 years (Standard Deviation $=6.52$ ). The majority of women were housewives (98.6\%) and lived out of the main city of the district (92.1\%). Two ethnic groups were mainly represented: Mossi (42.3\%) and Bwaba (39.6\%), and only $8.4 \%$ were Fulani. Islam was the dominant religion (52.1\%) and $98.9 \%$ of the participants were married with a proportion of monogamous (49.4\%) almost equivalent to the polygamous group (49.5\%). The literacy rate was very low at $15.1 \%$. Only $0.03 \%$ of women had a higher education.

The average number of pregnancies was 3.8 (SD: 2.5 pregnancies, range: $1-15)$. More than one-third (35\%) of the studied population had already more than four pregnancies. Parity average stood at 3.3 births (SD: 2.2 births; range: 013). A bad obstetric history-like abortion and stillbirth were recorded, respectively, with $22.2 \%$ and $5.5 \%$. The average number of living children for each woman was 2.5 (SD: 1.8; range: $0-12$ ).

3.2. Prevalence of Anaemia during Pregnancy. The mean haemoglobin level was $10.4 \mathrm{~g} / \mathrm{dL}$ (SD: $1.6 \mathrm{~g} / \mathrm{dL}$, range 3.3-16.7) and the prevalence of maternal anaemia $63.1 \%(1,887 / 2,990)$. The prevalence of maternal anaemia was highest among primigravidae in the second trimester of pregnancy $(71.8 \%$, 95\% CI: 66.9-76.6). Figure 1 displays the severity of anaemia among pregnant women. The majority of pregnant women in our study had moderate anaemia.

3.3. Prevalence of Nutritional Factors and Anaemia. The nutritional status indicators of pregnant women recruited in our study are displayed in Table 1 . The mean weight of pregnant women was $58.3 \mathrm{~kg}$ (SD: 7,3 kg, range 36-118). Only $7.2 \%$ of women were chronically undernourished with a body mass index $<19 \mathrm{~kg} / \mathrm{m}^{2}$. Reported consumption of alcohol was mainly related to the local millet beer called "dolo." Less than $20 \%$ of women reported consuming soil or kaolin from the beginning of their pregnancy.

3.4. Prevalence of Anaemia and Infectious Diseases. The results of infectious diseases are displayed in Table 2. For malaria, only Plasmodium falciparum species was identified.

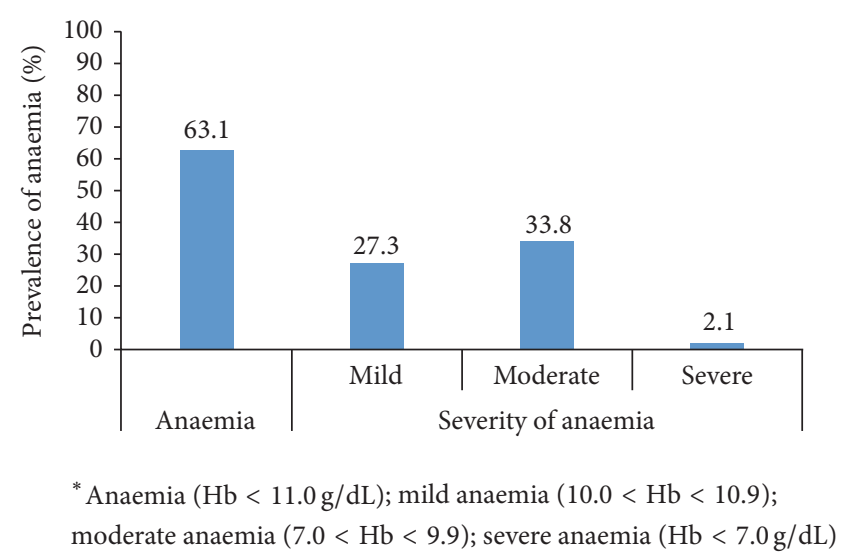

FIgure 1: Distribution of types* of maternal anaemia in Houndé health district, Burkina Faso.

TABLE 1: Nutritional status of pregnant women in Houndé health district, Burkina Faso.

\begin{tabular}{lccc}
\hline Characteristics & \multicolumn{2}{c}{ Total pregnant } & Prevalence of \\
& women surveyed & Pnaemia (95\% CI) \\
& $n$ & $\%$ & \\
\hline Weight & & & \\
$\quad<50 \mathrm{~kg}$ & 303 & 9.8 & $68.7 \%(63.0-73.8)$ \\
$\quad \geq 50 \mathrm{~kg}$ & 2,773 & 90.2 & $62.1 \%(60.0-64.0)$ \\
Brachial perimeter & & & \\
$\quad<24 \mathrm{~cm}$ & 597 & 23.7 & $70.0 \%(66.0-73.6)$ \\
$\quad \geq 24 \mathrm{~cm}$ & 1,917 & 76.3 & $61.4 \%(59.1-63.5)$ \\
Body mass index & & & \\
$\quad<19 \mathrm{~kg} / \mathrm{m}^{2}$ & 214 & 7.2 & $69.7 \%(62.9-75.7)$ \\
$\quad \geq 19 \mathrm{~kg} / \mathrm{m}^{2}$ & 2,742 & 92.8 & $62.3 \%(60.4-64.1)$ \\
Alcohol consumption & & & \\
$\quad$ Yes & 1,934 & 38.1 & $60.1 \%(57.2-62.9)$ \\
$\quad$ No & 1,934 & 61.9 & $64.6 \%(62.3-66.8)$ \\
Geophagy & & & \\
$\quad$ Yes & 508 & 16.3 & $69.8 \%(65.4-73.9)$ \\
$\quad$ No & 2,611 & 83.7 & $61.6 \%(59.6-63.5)$ \\
Vitamin A & & & \\
$\quad<20 \mu \mathrm{g} / \mathrm{dL}$ & 219 & 69.3 & $29.9 \%(24.1-36.6)$ \\
$\quad 20 \mu \mathrm{g} / \mathrm{dL}$ & 97 & 30.7 & $25.0 \%(17.0-35.2)$ \\
\hline
\end{tabular}

Median malaria parasite density was 600 trophozoites $/ \mathrm{mm}^{3}$ and the mean was 828 trophozoites $/ \mathrm{mm}^{3}$ (SD: 852.4; range 96-4800). For helminthiases, $21 \%$ of pregnant women had at least one parasite. Polyparasitism was rare $(0,4 \%)$. The prevalence of anaemia in the presence of viral and bacterial infections was not exceeding the average figure observed in the study population.

3.5. Factors Associated with Maternal Anaemia. Table 3 shows the unadjusted factors associated with anaemia in our study. Maternal anaemia was significantly associated with Fulani ethnic group $(P<0.01)$, Muslin religion $(P=0.05)$, 
TABLE 2: Prevalence of infectious diseases among pregnant women in Houndé health district, Burkina Faso.

\begin{tabular}{|c|c|c|c|c|c|}
\hline \multirow{2}{*}{ Type of disease } & \multirow{2}{*}{ Sample tested } & \multicolumn{3}{|c|}{ Positive tests } & \multirow{2}{*}{$\begin{array}{l}\text { Prevalence of anaemia } \\
\text { among women positives }\end{array}$} \\
\hline & & $n$ & $\%$ & $95 \% \mathrm{CI}$ & \\
\hline HIV & 3,140 & 51 & 1.62 & $1.10-2.06$ & $63.8 \%$ \\
\hline Gonorrhoea & 1,699 & 13 & 0.77 & $0.35-1.17$ & $72.7 \%$ \\
\hline Chlamydia & 199 & 14 & 7.04 & $3.45-10.61$ & $46.1 \%$ \\
\hline Herpes simplex virus 2 & 460 & 104 & 22.61 & $18.77-26.44$ & $66.7 \%$ \\
\hline Trichomoniasis & 3,019 & 488 & 16.16 & $14.85-17.47$ & $63.9 \%$ \\
\hline Candidiasis & 1,748 & 398 & 22.77 & $20.80-24.73$ & $63.0 \%$ \\
\hline Bacterial vaginoses & 2,994 & 558 & 18.64 & $17.24-20.03$ & $62.6 \%$ \\
\hline Syphilis TPHA+ & 3,140 & 114 & 3.63 & $2.97-4.28$ & $64.0 \%$ \\
\hline Syphilis TPHA/RPR+ & 3,140 & 22 & 1.82 & $1.06-2.57$ & $63.3 \%$ \\
\hline Malaria & 3,043 & 141 & 4.63 & $3.88-5.38$ & $69.7 \%$ \\
\hline Helminthiases & 2,842 & 594 & 20.9 & $19.40-22.39$ & $62.2 \%$ \\
\hline
\end{tabular}

and no education $(P=0.01)$. Conversely, age $(P=0.08)$, marital status $(P=0.58)$, and occupation $(P=0.06)$ were not associated with maternal anaemia.

All the nutritional indicators assessed were associated with maternal anaemia, except vitamin A. Thus, women who regularly consumed alcoholic beverages were significantly $(P<0.01)$ more anaemic than those who did not. The prevalence of anaemia was significantly $(P<0.001)$ higher among geophagic women. Similarly, a body mass index $<19 \mathrm{~kg} / \mathrm{m}^{2}(P=0.01)$, a maternal weight $<50 \mathrm{~kg}(P=0.01)$, and brachial perimeter $<24 \mathrm{~cm}(P \leq 0.001)$ were significantly and strongly associated with anaemia.

Among gynaecological and obstetric factors potentially associated with anaemia, only the number of pregnancies was statistically significant $(P=0.01)$. Thus, anaemia was significantly more prevalent among primigravidae compared to paucigest or multigest patients. Parity and abortion did not appear to be associated with maternal anaemia.

No association was found to be statically significant between anaemia and helminthiasis $(P=0.58)$, STDs, HIV $(P=0.6)$, and malaria $(P=0.08)$.

The multivariate logistic regression identified four main factors statistically and independently associated with maternal anaemia in the district of Houndé: geophagy $(P=0.04)$, education $(P=0.04)$, number of pregnancies $(P=0.001)$, and brachial perimeter inferior to $24 \mathrm{~cm}(P=0.003)$.

\section{Discussion}

In order to help define an appropriate and effective national intervention strategy to better control maternal anaemia, our research outcome highlighted the magnitude of maternal anaemia (63.1\%). Multivariate logistic regression indicated an association between anaemia and four factors: geophagy, education, number of pregnancies, and brachial perimeter. But no infectious disease was associated with maternal anaemia.

A potential of selection bias could be generated because of the inclusion process concerned only with pregnant women coming for antenatal consultation. However, the compensation provided in the study could have minimised it, by attracting some of the pregnant women who did not use to go to frequent health centres.

The study was conducted between March and June of the year 2010. This period corresponds to the end of dry season and the beginning of the rainy season; these conditions are not favourable to malaria Anopheles vector proliferation [17]. Likewise, dry season is not the most favourable period for helminth transmission [18]. But it would have been difficult to complete the study during raining season because of transport link failure and movement of people from villages to farming hamlets. This seasonality effect of malaria and helminthiasis transmission could lower the prevalence rate of Plasmodium and helminth infection and that of anaemia which can be a possible complication of these affections [19].

Another limitation of the study was related to the health centre personnel who carried out the different tests. In spite of their training at the beginning of the study, they had enormous difficulties to properly implement microbiological sampling. This limit greatly reduced the number of subjects screened for Neisseria gonorrhoeae and Chlamydia trachomatis.

Finally, investigators had difficulties in asking questions related to women' habits and behaviour. Thus, a prevarication bias has to be underlined. Likewise, some women were reluctant to answer questions relating to privacy, bringing considerable missing data.

The magnitude of maternal anaemia appeared high in the health district of Houndé (63\%) and proved to be consistent with WHO estimate for the country (68\%) in 2008 [2]. This figure seems also comparable to the previous estimates of maternal anaemia in the urban areas of Burkina Faso [12, 13].

Health risks related to nutritional factors were also high, with vitamin A deficiency prevalence approximating 69\% and geophagy $16 \%$. But the figure related to vitamin A deficiency seems comparable to the estimates provided in the last decade for Africa [20]. But, for geophagy, the prevalence found in this study appeared low compared to the previous estimate (30\%) 
TABLE 3: Factors associated with maternal anaemia in Houndé health district, Burkina Faso, univariable analysis.

\begin{tabular}{|c|c|c|c|c|c|}
\hline \multirow{3}{*}{ Characteristic } & \multicolumn{4}{|c|}{ Anaemia } & \multirow{3}{*}{$P$} \\
\hline & \multicolumn{2}{|c|}{ Yes } & \multicolumn{2}{|c|}{ No } & \\
\hline & $(n)$ & $(\%)$ & $(n)$ & $(\%)$ & \\
\hline \multicolumn{6}{|l|}{ Age } \\
\hline$<20$ years & 421 & 66.3 & 214 & 33.7 & \multirow{3}{*}{0.08} \\
\hline $20-34$ years & 1249 & 62.8 & 741 & 37.2 & \\
\hline$\geq 35$ years & 199 & 59.4 & 136 & 40.6 & \\
\hline \multicolumn{6}{|l|}{ Occupation } \\
\hline Housewife & 1852 & 63.3 & 1072 & 36.7 & \multirow{2}{*}{0.06} \\
\hline Others & 20 & 47.6 & 22 & 52.4 & \\
\hline \multicolumn{6}{|l|}{ Ethnic group } \\
\hline Mossi & 771 & 58.8 & 541 & 41.2 & \multirow{4}{*}{$<0.01$} \\
\hline Bwaba & 708 & 57.4 & 525 & 42.6 & \\
\hline Fulani & 157 & 64.1 & 88 & 35.9 & \\
\hline Others & 191 & 60.6 & 124 & 39.4 & \\
\hline \multicolumn{6}{|l|}{ Body mass index } \\
\hline$<19 \mathrm{~kg} / \mathrm{m}^{2}$ & 253 & 71.4 & 128 & 28.6 & \multirow{2}{*}{0.01} \\
\hline$\geq 19 \mathrm{~kg} / \mathrm{m}^{2}$ & 1634 & 62.6 & 975 & 37.4 & \\
\hline \multicolumn{6}{|l|}{ Weight } \\
\hline$<50 \mathrm{~kg}$ & 202 & 69.9 & 87 & 30.1 & \multirow{2}{*}{0.01} \\
\hline$\geq 50 \mathrm{~kg}$ & 1643 & 62.4 & 992 & 37.6 & \\
\hline \multicolumn{6}{|l|}{ Brachial perimeter } \\
\hline$<24 \mathrm{~cm}$ & 718 & 69.7 & 312 & 30.3 & \multirow{2}{*}{$<0.001$} \\
\hline$\geq 24 \mathrm{~cm}$ & 796 & 59.4 & 544 & 40.6 & \\
\hline \multicolumn{6}{|l|}{ Number of pregnancies } \\
\hline Primigravidae & 415 & 67.8 & 197 & 32.2 & \multirow{3}{*}{0.01} \\
\hline $\begin{array}{l}\text { Paucigravidae (2 to } 4 \\
\text { pregnancies) }\end{array}$ & 826 & 63.1 & 484 & 36.9 & \\
\hline Multigravidae ( $\geq 5$ pregnancies) & 631 & 60.6 & 411 & 39.4 & \\
\hline \multicolumn{6}{|l|}{ Parity } \\
\hline Primiparity & 354 & 65.7 & 185 & 34.3 & \multirow{4}{*}{0.18} \\
\hline Pauciparity (1 to 4 deliveries) & 674 & 61.1 & 429 & 38.9 & \\
\hline $\begin{array}{l}\text { Grand multiparity (5 to } 7 \\
\text { deliveries) }\end{array}$ & 321 & 60.6 & 209 & 39.4 & \\
\hline Great grand multiparity $(\geq 8)$ & 71 & 57.7 & 52 & 42.3 & \\
\hline \multicolumn{6}{|l|}{ Intestinal helminthiases } \\
\hline Yes & 358 & 62.6 & 214 & 37.4 & \multirow{2}{*}{0.58} \\
\hline No & 1534 & 63.6 & 781 & 36.2 & \\
\hline \multicolumn{6}{|l|}{ Geophagy } \\
\hline Yes & 334 & 70.9 & 137 & 29.1 & 0.001 \\
\hline No & 1534 & 61.7 & 953 & 38.3 & $<0.001$ \\
\hline HIV infection & & & & & \\
\hline Yes & 32 & 66.7 & 16 & 33.3 & 06 \\
\hline No & 1855 & 63.1 & 1087 & 36.9 & \\
\hline Malaria & & & & & \\
\hline Yes & 95 & 70 & 40 & 29.6 & 0.08 \\
\hline No & 1792 & 62.8 & 1063 & 37.2 & 0.08 \\
\hline
\end{tabular}

made in the urban area of Bobo-Dioulasso in Burkina Faso [13].

Genital herpes, trichomoniasis, bacterial vaginosis, and vaginal candidiasis reached prevalence of $23 \%, 16 \%, 13 \%$, and 23\%, respectively. These proportions of STDs were comparable to those found in 1997 among pregnant women in urban areas of Ouagadougou and Bobo-Dioulasso [21]. As for Neisseria gonorrhoeae infection, our study observed a low prevalence of syphilis $(0.9 \%)$, confirmed by Sombié et al. findings in urban Burkina Faso [22]. Lastly, HIV infection rate $(1.6 \%)$ was low when compared to Sangare et al. study which showed a prevalence rate of (8\%) in urban area [23].

Intestinal helminths were a common pathology among pregnant women in health district of Houndé, with roughly $21 \%$ of pregnant women harbouring at least one helminth. Hookworm was the most frequent parasite (with $12 \%$ of women infected). Determinant factors like poor hygiene and sanitation should be pointed out [24]. However, our figures appeared low compared to the results of a similar study conducted in Gabon where 49\% of pregnant women were infected with intestinal helminths [25].

Malaria prevalence was roughly $5 \%$ in the district of Houndé which is a zone of high seasonal transmission of malaria. As indicated before, the period of our study was at the low transmission season. A cross-sectional survey conducted in the neighbouring district of Boromo (Burkina Faso) confirmed the suspicion of low malaria prevalence during a similar period [26]. But, during the high transmission season, higher prevalence was recorded among pregnant women, almost 32\% in December [26]. In addition to the study period, the low prevalence of malaria could be explained by the pregnant women antimalarial chemoprophylaxis, as $60 \%$ of study population already benefitted from it at their inclusion.

Logistic regression indicated that anaemia was independently associated with low education. Indeed, mothers who have spent a longer time at school presented better knowledge of health care, improved capacity to employ the family income rationally, better employment, and remuneration prospects which in turn better nutritional status [27]. Equally, in the Lak district, Daklak province of Vietnam, Trinh et al. showed an association between anaemia and education, in their cross-sectional survey among pregnant women [28].

Low brachial perimeter was also found to be independently associated with maternal anaemia. Having a brachial perimeter inferior to $24 \mathrm{~cm}$ is well known as a symptom of malnutrition, characterized by various micronutrient deficiencies resulting in anaemia among pregnant women [29].

Geophagy was also well known to be a risk factor of maternal anaemia, as consuming kaolin (clay) was associated with anaemia [30]. Geophagy could cause haematophagous parasitic infections such as ankylostomiasis and trichocephalus which may ultimately end in anaemia [30]. In 1998, Geissler et al. explained in their cross-sectional study among primary school children in Western Kenya that the amount of food ingested could act as a confounder of the studied relationship between geophagy and iron nutrition $[31,32]$. Certain soil components could also reduce the bioavailability of dietary iron [30]. In addition, the ingested soil could damage the intestinal mucosa, leading to reduced iron uptake. Moreover, aluminium can reduce serum ferritin and deplete iron stores [30]. 
Furthermore, high number of pregnancies (multigravidae) was likely to be a protective factor for anaemia. This association between anaemia and number of pregnancies is related to malaria effect on haemoglobin level. Malaria is known to cause anaemia by the phenomenon of erythrocyte haemolysis. Primigravidas tend to have lower immunity and can suffer more severely from malaria than multigravidas $[33,34]$.

No association was found between maternal anaemia and vitamin A deficiency or infectious diseases selected for the study. If anaemia can be seen as an affection which appears to be the complications of nutritional deficiencies and infectious diseases, our study design was not the best one to assess the link between them. In effect, cross-sectional studies are suitable to estimate the prevalence of phenomena, but, regarding causality relationship, their evidence is weak [35].

\section{Conclusion}

The prevalence of maternal anaemia was found very high, $63.1 \%$. Logistic regression demonstrated that maternal anaemia was independently associated with geophagy, low brachial perimeter, low education, and number of pregnancies (primigravida). Maternal anaemia should be addressed by adequate policy including education and the fight against malnutrition.

\section{Competing Interests}

The authors declare that there is no conflict of interests regarding the publication of this paper.

\section{Authors' Contributions}

Nicolas Meda developed the concept, participated in data collection and analysis, and wrote the paper. Malik Coulibaly was involved in data analysis and critically reviewed the paper. Yacouba Nebie, Ibrahima Diallo, and Yves Traore participated in data collection and analysis. Laurent T. Ouedraogo participated in concept development and critically reviewed the paper. All the authors read and approved the final paper.

\section{Acknowledgments}

This study received part financial support for data collection from European Commission through the "SAREDO Programme." All the health personnel, stakeholders, partners, and community members who willingly participated in this study are hereby acknowledged.

\section{References}

[1] G. A. Stevens, M. M. Finucane, L. M. De-Regil et al., "Global, regional, and national trends in haemoglobin concentration and prevalence of total and severe anaemia in children and pregnant and non-pregnant women for 1995-2011: a systematic analysis of population-representative data," The Lancet Global Health, vol. 1, no. 1, pp. E16-E25, 2013.

[2] World Health Organization, Worldwide Prevalence of Anaemia 1993-2005 : WHO Global Database on Anaemia, World Health Organization, Geneva, Switzerland, 2008.

[3] N. van den Broek, "Anaemia and micronutrient deficiencies," British Medical Bulletin, vol. 67, pp. 149-160, 2003.

[4] N. van den Broek, "The aetiology of anaemia in pregnancy in West Africa," Tropical Doctor, vol. 26, no. 1, pp. 5-7, 1996.

[5] F. P. Mockenhaupt, B. Rong, M. Günther et al., "Anaemia in pregnant Ghanaian women: importance of malaria, iron deficiency, and haemoglobinopathies," Transactions of the Royal Society of Tropical Medicine and Hygiene, vol. 94, no. 5, pp. 477483, 2000.

[6] M. Malhotra, J. B. Sharma, S. Batra, S. Sharma, N. S. Murthy, and R. Arora, "Maternal and perinatal outcome in varying degrees of anemia," International Journal of Gynecology and Obstetrics, vol. 79, no. 2, pp. 93-100, 2002.

[7] J. Villar, M. Merialdi, A. M. Gülmezoglu et al., "Nutritional interventions during pregnancy for the prevention or treatment of maternal morbidity and preterm delivery: an overview of randomized controlled trials," Journal of Nutrition, vol. 133, no. 5, pp. 1606S-1625S, 2003.

[8] R. Galloway, E. Dusch, L. Elder et al., "Women's perceptions of iron deficiency and anemia prevention and control in eight developing countries," Social Science and Medicine, vol. 55, no. 4, pp. 529-544, 2002.

[9] B. C. Seck and R. T. Jackson, "Determinants of compliance with iron supplementation among pregnant women in Senegal," Public Health Nutrition, vol. 11, no. 6, pp. 596-605, 2008.

[10] C. Miaffo, F. Some, B. Kouyate, A. Jahn, and O. Mueller, "Malaria and anemia prevention in pregnant women of rural Burkina Faso," BMC Pregnancy \& Childbirth, vol. 4, article 18, 2004.

[11] R. Hughes, "Climate change and the public health nutrition agenda," Public Health Nutrition, vol. 13, no. 3, p. 303, 2010.

[12] N. Meda, S. Cousens, and B. Kanki, "Anaemia among women of reproductive age in Burkina Faso," World Health Forum, vol. 17, no. 4, pp. 369-372, 1996.

[13] N. Meda, Y. Dao, B. Touré, B. Yameogo, S. Cousens, and W. Graham, "Assessing severe maternal anemia and its consequences: the value of a simple examination of the coloration of palpebral conjunctiva," Cahiers Santé, vol. 9, no. 1, pp. 12-17, 1999.

[14] N. Meda, L. Mandelbrot, M. Cartoux, B. Dao, A. Ouangré, and F. Dabis, "Anaemia during pregnancy in Burkina Faso, West Africa, 1995-96: prevalence and associated factors. DITRAME Study Group," Bulletin of the World Health Organization, vol. 77, no. 11, pp. 916-922, 1999.

[15] N. Meda, L. Gautier-Charpentier, R. B. Soudré et al., "Serological diagnosis of human immunodeficiency virus in Burkina Faso: reliable, practical strategies using less expensive commercial test kits," Bulletin of the World Health Organization, vol. 77, no. 9, pp. 731-739, 1999.

[16] J. S. Jahr, F. Lurie, B. Driessen, J. A. Davis, R. Gosselin, and R. A. Guther, "The HemoCue ${ }^{\circledR}$, a point of care B-hemoglobin photometer, measures hemoglobin concentrations accurately when mixed in vitro with canine plasma and three hemoglobin-based oxygen carriers (HBOC)," Canadian Journal of Anesthesia, vol. 49, no. 3, pp. 243-248, 2002.

[17] Z. Bisoffi, S. B. Sirima, J. Menten et al., "Accuracy of a rapid diagnostic test on the diagnosis of malaria infection and of malaria-attributable fever during low and high transmission 
season in Burkina Faso," Malaria Journal, vol. 9, no. 1, article 192, 2010.

[18] V. Hanitrasoamampionona, L. Brutus, G. Hébrard et al., "Epidemiological study of main human intestinal helminthiasis in the middle west of Madagascar," Bulletin de la Société de Pathologie Exotique, vol. 91, no. 1, pp. 77-80, 1998.

[19] G. T. Bondevik, R. T. Lie, M. Ulstein, and G. Kvåle, "Seasonal variation in risk of anemia among pregnant Nepali women," International Journal of Gynecology and Obstetrics, vol. 69, no. 3, pp. 215-222, 2000.

[20] K. P. West Jr., "Extent of vitamin A deficiency among preschool children and women of reproductive age," Journal of Nutrition, vol. 132, pp. 2857S-2866S, 2002.

[21] N. Meda, L. Sangaré, S. Lankoandé et al., "Pattern of sexually transmitted diseases among pregnant women in Burkina Faso, west Africa: potential for a clinical management based on simple approaches," Genitourinary Medicine, vol. 73, no. 3, pp. 188-193, 1997.

[22] I. Sombié, N. Meda, M. Cartoux et al., "Seroprevalence of syphilis among women attending urban antenatal clinics in Burkina Faso, 1995-1998," Sexually Transmitted Infections, vol. 76, no. 4, pp. 314-316, 2000.

[23] L. Sangaré, N. Meda, S. Lankoandé et al., "HIV infection among pregnant women in Burkina Faso: a nationwide serosurvey," International Journal of STD and AIDS, vol. 8, no. 10, pp. 646651, 1997.

[24] S. Brooker, A. C. A. Clements, and D. A. P. Bundy, "Global epidemiology, ecology and control of soil-transmitted helminth infections," Advances in Parasitology, vol. 62, pp. 221-261, 2006.

[25] A. A. Adegnika, M. Ramharter, S. T. Agnandji et al., "Epidemiology of parasitic co-infections during pregnancy in Lambaréné, Gabon," Tropical Medicine and International Health, vol. 15, no. 10, pp. 1204-1209, 2010.

[26] S. O. Coulibaly, S. Gies, and U. D’Alessandro, "Malaria burden among pregnant women living in the rural district of Boromo, Burkina Faso," American Journal of Tropical Medicine and Hygiene, vol. 77, no. 6, pp. 56-60, 2007.

[27] M. A. A. Oliveira, M. M. Osório, and M. C. F. Raposo, "Socioeconomic and dietary risk factors for anemia in children aged 6 to 59 months," Jornal de Pediatria, vol. 83, no. 1, pp. 3946, 2007.

[28] L. T. T. Trinh and M. Dibley, "Anaemia in pregnant, postpartum and non pregnant women in Lak district, Daklak province of Vietnam," Asia-Pacific Journal of Clinical Nutrition, vol. 16, no. 2, pp. 310-315, 2007.

[29] A. A. Olukoya and O. F. Giwa-Osagie, "Maternal weight and weight gain during pregnancy-can the arm circumference be used as surrogate?" African Journal of Medicine \& Medical Sciences, vol. 20, no. 2, pp. 155-162, 1991.

[30] K. Kawai, E. Saathoff, G. Antelman, G. Msamanga, and W. W. Fawzi, "Geophagy (soil-eating) in relation to anemia and helminth infection among HIV-infected pregnant women in Tanzania," The American Journal of Tropical Medicine and Hygiene, vol. 80, no. 1, pp. 36-43, 2009.

[31] P. W. Geissler, D. Mwaniki, F. Thiong'o, and H. Friis, "Geophagy as a risk factor for geohelminth infections: a longitudinal study of Kenyan primary schoolchildren," Transactions of the Royal Society of Tropical Medicine and Hygiene, vol. 92, no. 1, pp. 7-11, 1998.

[32] E. Saathoff, A. Olsen, J. D. Kvalsvig, and W. P. Geissler, "Geophagy and its association with geohelminth infection in rural schoolchildren from northern KwaZulu-Natal, South Africa," Transactions of the Royal Society of Tropical Medicine and Hygiene, vol. 96, no. 5, pp. 485-490, 2002.

[33] C. O. Agomo and W. A. Oyibo, "Factors associated with risk of malaria infection among pregnant women in Lagos, Nigeria," Infectious Diseases of Poverty, vol. 2, article 19, 2013.

[34] T. Staalsoe, C. E. Shulman, J. N. Bulmer, K. Kawuondo, K. Marsh, and L. Hviid, "Variant surface antigen-specific IgG and protection against clinical consequences of pregnancyassociated Plasmodium falciparum malaria," The Lancet, vol. 363, no. 9405, pp. 283-289, 2004.

[35] J. M. Stephenson and A. Babiker, "Overview of study design in clinical epidemiology," Sexually Transmitted Infections, vol. 76, no. 4, pp. 244-247, 2000. 


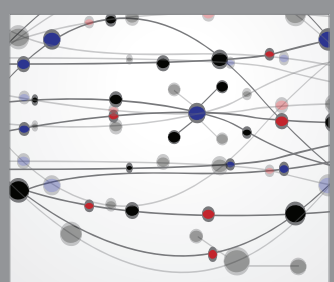

The Scientific World Journal
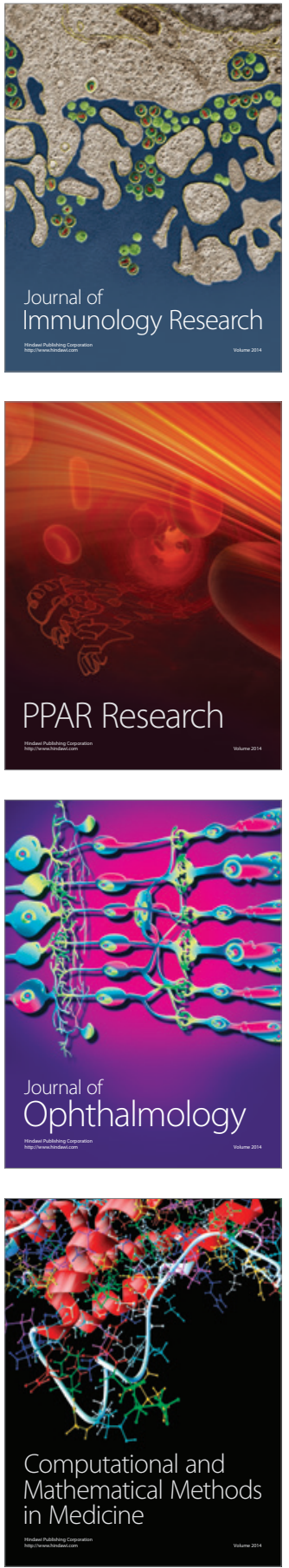

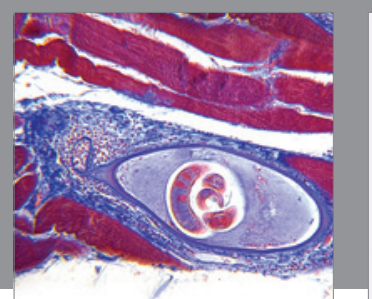

Gastroenterology Research and Practice

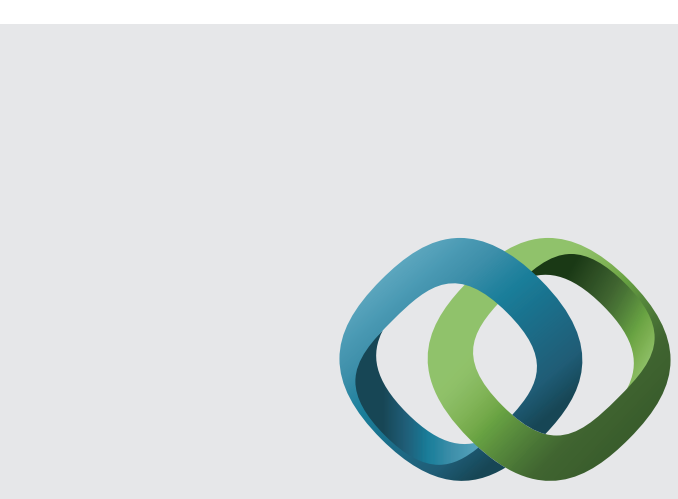

\section{Hindawi}

Submit your manuscripts at

http://www.hindawi.com
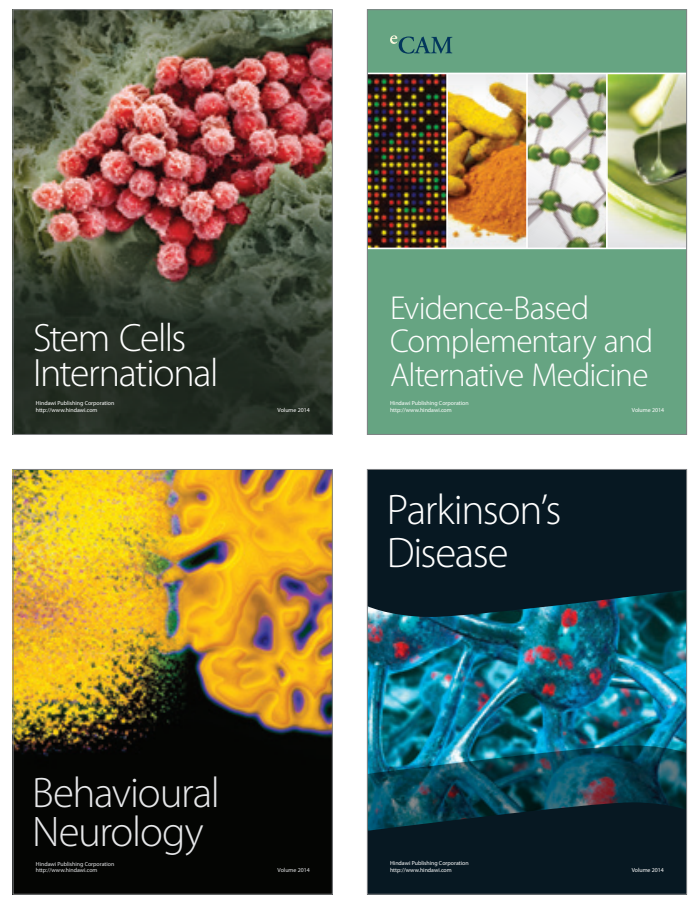
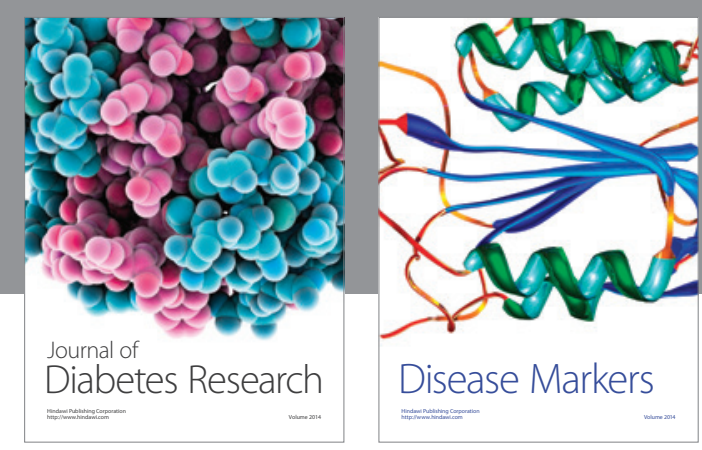

Disease Markers
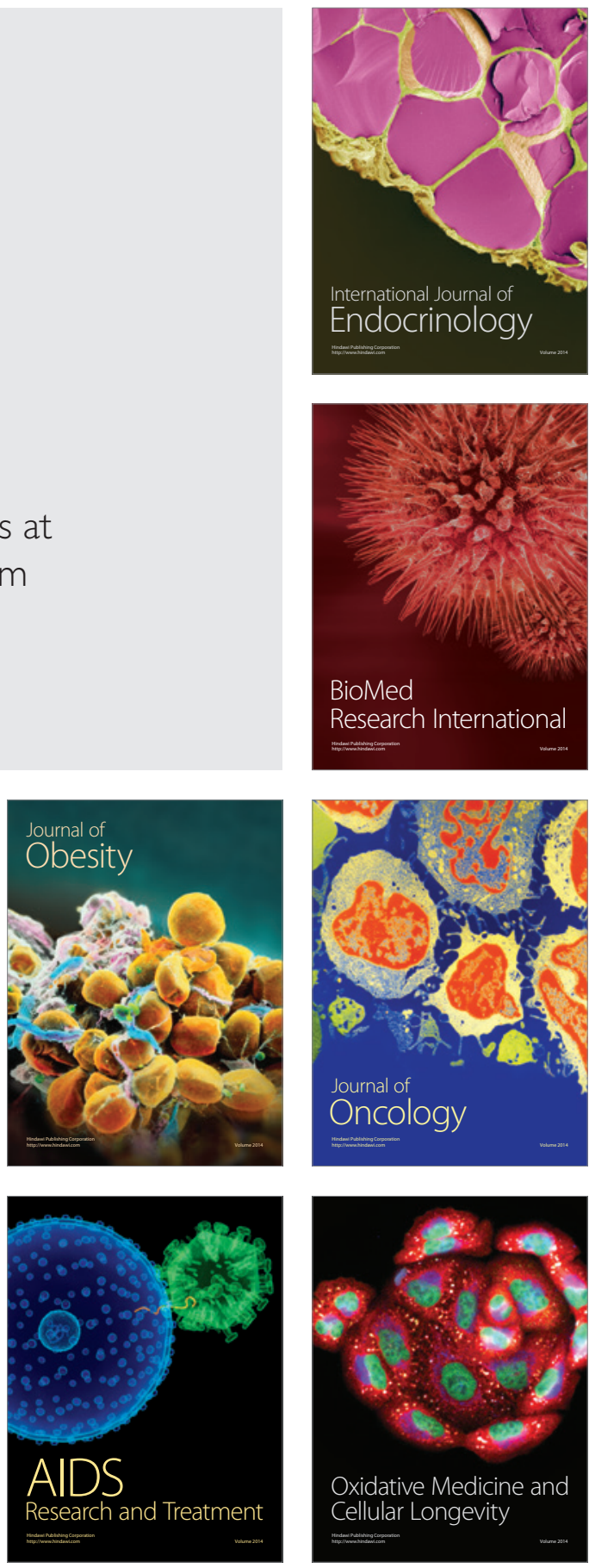